 \\ Vulnerabilidad y bioética
}

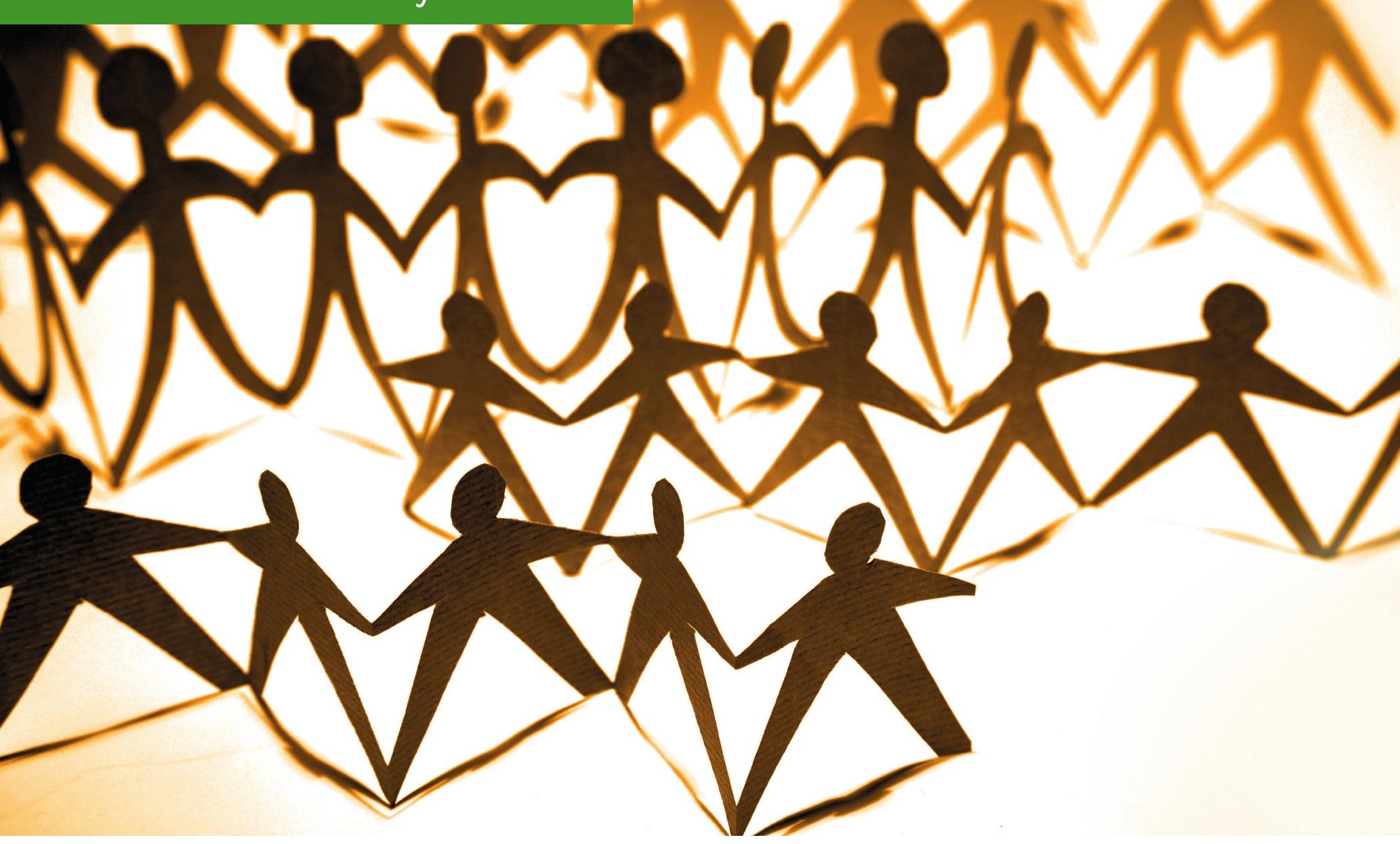

Categorização dos sujeitos em condição de vulnerabilidade: uma revisão na perspectiva da bioética

Categorization of subjects in vulnerability condition: a review in the bioethics perspective

(2) Autor
Ricardo de Amorim Cini

Mestrando do Programa de Pós-graduação em Bioética da PUCPR. Curitiba, Paraná, Brasil E-mail: riicardo.cini@hotmail.com

Caroline Filla Rosaneli

Pós-doutoranda pela Cátedra UNESCO em Bioética da Universidade de Brasília. Docente do Programa de Pós-graduação em Bioética da PUCPR. Curitiba, Paraná, Brasil

E-mail: caroline.rosaneli@gmail.com

\section{Anor Sganzerla}

Doutor em Filosofia pela UFSCar. Docente do Programa de Pós-graduação em Bioética da PUCPR.

Curitiba, Paraná, Brasil

E-mail: anor.sganzerla@gmail.com 


\section{Resumo}

A utilização da expressão vulnerabilidade no discurso da bioética, como conceito ou realidade, tornou-se cada vez mais recorrente. Seu primeiro e mais importante uso se deu na proteção de sujeitos em experimentos, mas expandiu-se para outras situações. Esta pesquisa buscou categorizar quem são esses sujeitos ou realidades classificadas como vulneráveis através de uma busca nas bases de dados Scielo.BR, Scielo.ORG e Lilacs, utilizando os descritores "bioética" e "vulnerabilidade". Através da análise de 79 artigos, identificaram-se quatro grandes categorias agrupadas em vulnerabilidade enquanto: [1] fases da vida e gênero; [2] saúde, doença e pesquisa; [3] exclusões sociais, econômicas, culturais e políticas; [4] e meio ambiente. Essa categorização demonstra que a reflexão da bioética a respeito da vulnerabilidade ainda é predominantemente antropocêntrica, tornando a proteção da dignidade da vida em sua totalidade ainda um desafio a ser enfrentado pelo seu discurso.

The use of the term vulnerability in the discussion of bioethics, either as a concept or as a reality, has become increasingly recurrent. The first, and also most important use of this term is to protect subjects participating in experiments, but its use has been expanded to other situations. The aim of this research was to identify the subjects or realities that are classified as vulnerable. We used the descriptors "bioethics" and "vulnerability" to search for literature in Scielo.BR, Scielo.ORG and Lilacs, and analyzed 79 articles. Furthermore, in these articles we identified four categories of vulnerability that can be grouped as vulnerability in: [1] stages of life and gender; [2] health, disease and research; [3] socioeconomic and cultural exclusion; [4] and environment. This categorization demonstrates that the bioethical reflection on the vulnerability of life is still predominantly anthropocentric, which makes the protection of the dignity of life as a whole a challenge that is still to be faced by bioethical discussion.

Key words Vulnerabilidade; bioética; vida humana; extra-humana.

Vulnerability; bioethics; human life; extra-human. 


\section{Introduçao}

O conceito de vulnerabilidade vem sendo tratado na bioética, com mais frequência na perspectiva da saúde, pela complexidade de lidar com esta área, rodeada de problemas socioeconômicos e dificuldades enfrentadas pelos profissionais que nela atuam (L. D. Almeida, 2010). Também é recorrente a perspectiva da vulnerabilidade como um fato encontrado em um grupo de indivíduos e que deve, desse modo, ser tratada e combatida (Neves, 2006). O Relatório Belmont, o qual indicou preceitos éticos que devem ser respeitados para fundamentar a experimentação envolvendo sujeitos humanos sendo a primeira fonte de utilização da vulnerabilidade no âmbito da preocupação ética (Neves, 2006) - ressalta a preocupação com essa categoria na seleção de sujeitos para a realização de experimentos. Indica o relatório que:

Um caso especial de injustiça resulta do envolvimento de sujeitos vulneráveis. Certos grupos, como as minorias raciais, os economicamente desfavorecidos, os muito doentes e os institucionalizados podem ser buscados continuamente como sujeitos de pesquisa, devido à sua pronta disponibilidade em ambientes onde a pesquisa é conduzida. Dado seu status dependente e sua capacidade frequentemente comprometida de consentimento livre, eles devem ser protegidos contra o perigo de serem envolvidos na pesquisa apenas por conveniência administrativa, ou porque são fáceis de manipular, resultante de sua doença ou condição socioeconômica (The National Commission for the Protection of Human Subjects of Biomedical and Behavioral Research [NCPHSBB], 1979, p.19-20, tradução nossa).

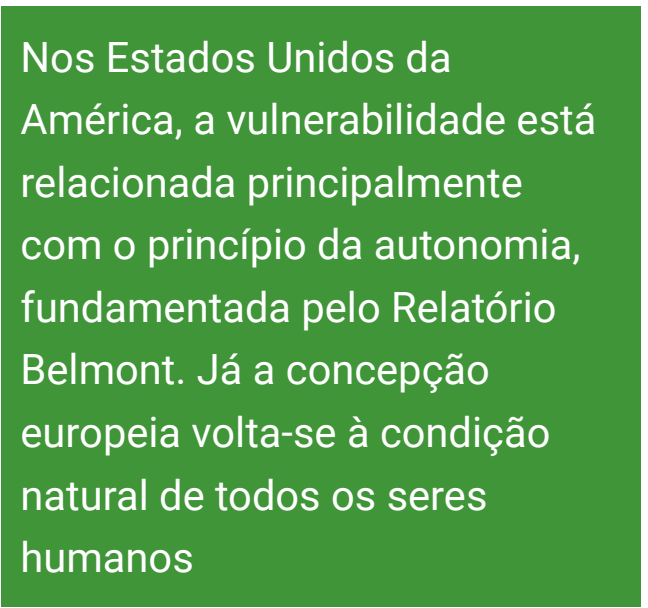

Ou seja, inicialmente a vulnerabilidade era uma condição utilizada somente na proteção de sujeitos envolvidos em experimentos. Entretanto, Neves (2006) indicou que a partir dos anos 1990, ampliou-se este conceito, utilizando-a então como um princípio, sendo vista como característica e também como condição.

Cunha e Garrafa (2017) apresentaram diferentes interpretações de vulnerabilidade a partir da busca de um conceito global, concomitantemente as preocupações da bioética em diferentes regiões. Nos Estados Unidos da América, afirmaram os autores, ela está relacionada principalmente com o princípio da autonomia, fundamentada pelo Relatório Belmont. Já a concepção europeia volta-se à condição natural de todos os seres humanos. Destacaram também os pesquisadores, que não se encontra um conceito originado da bioética na África. Na Ásia, por sua vez, devido a sua extensão e diversidade cultural e religiosa, não é possível indicar uma linha predominante, existindo diversos contextos que influenciam as perspectivas da bioética no continente. Por fim, na América Latina, as implicações do conceito de vulnerabilidade voltam-se às exclusões de origem socioeconômica, relacionado, portanto, aos aspectos sociais, com destaque nos experimentos e seus sujeitos em pesquisa. 
O esforço da Bioética de Intervenção no contexto latino-americano, a qual procurou incorporar questões de inclusão social na pauta da bioética, não pode ficar de fora ao tratar deste assunto, pois "a percepção da pessoa como uma totalidade somática na qual estão articuladas as dimensões física e psíquica" (Garrafa, 2005, p.127) precisa ser levada em conta. Também a Declaração Universal de Bioética e Direitos Humanos (DUBDH) em seus fundamentos, mostrou sua preocupação com o "respeito pela vulnerabilidade humana e integridade pessoal" (Organização das Nações Unidas para a Educação, a Ciência e a Cultura [UNESCO], 2006, art. $8^{\circ}$ ).

A compreensão de que a vida

é vulnerável e frágil encontrase

presente na filosofia de Hans

Jonas (2006), principalmente

diante do poder da técnica

moderna
Schramm (2008), em sintonia com a Bioética da Proteção (também presente na América Latina), como uma ferramenta de proteção para grupos que encontram nesta situação, propôs uma distinção entre vulnerabilidade, suscetibilidade e vulnerado. Para o autor, a primeira é a condição natural de todo o ser humano por existência, e por isso se torna suscetível a se tornar vulnerado, uma vez afetado por essa condição.

A compreensão de que a vida é vulnerável e frágil encontrase presente na filosofia de Hans Jonas (2006), principalmente diante do poder da técnica moderna. Para o autor, o homem com o poder da tecnociência passou a ameaçar a continuidade autêntica da vida humana e extra-humana no futuro. Paolo Becchi (2008), em sintonia com Jonas, em sua obra La vulnerabilità de la vita, reforça a tese de que a vida (humana e extra-humana) por ser livre, é frágil e vulnerável em sua essência, ou melhor, justamente por ser frágil é que é livre.

Nesta pesquisa utilizou-se do conceito de vulnerabilidade em sua amplitude, pois seu objetivo é identificar quem são os sujeitos em condição de vulnerabilidade presentes no discurso bioético.

\section{Metodologia}

Para levantamento do material bibliográfico, realizou-se uma busca no mês de abril de 2017 em três bases de dados online: [1] Scientific Eletronic Library Online (SciELO.ORG) com 52 resultados; [2] Scielo no Brasil (Scielo.BR) com 30 resultados; e na [3] Literatura Latino-Americana e do Caribe em Ciências da Saúde (Lilacs) com 70 resultados. Utilizaram-se como descritores os termos "bioética" e "vulnerabilidade" presente nas bases de dados dos anos 2008 a 2017, totalizando 152 resultados. Após a exclusão dos artigos duplicados restaram 82 artigos.

Com a finalidade de ordenar e sumarizar cada estudo foi realizado uma análise exploratória e criadas categorias analíticas com o intuito de identificar os sujeitos na condição de vulnerabilidade. Foram excluídos 3 resultados, pois neles não foi possível identificar quem eram estes sujeitos, totalizando, desse modo, 79 artigos para a categorização. Por fim, os trabalhos foram ordenados em quatro categorias: [1] Fases da vida e gênero; [2] Saúde, doença e pesquisa; [3] Condições de exclusões sociais, econômicas, culturais e políticas; [4] Meio ambiente. 
Ressalta-se que alguns sujeitos podem ser encaixados em mais de uma categoria, a exemplo, tem-se "Pacientes Idosos com Doença de Alzheimer" (Crippa, Loureiro \& Gomes, 2016), que se encaixam simultaneamente nas categorias 1 e 2. Além disso, é importante destacar que as bases de dados acessadas compilam literatura técnica e científica principalmente dos países da América Latina e Caribe, em português e espanhol e, como a busca foi realizada com os descritores em português, as publicações são majoritariamente dessas regiões, podendo, contudo, aparecer publicações em periódicos de países com língua portuguesa que não dessa região.

\section{Vulnerabilidade: categorias a partir dos sujeitos}

\subsection{Fases da vida e gênero}

Nesta categoria, foram correlacionados os subgrupos embriões, crianças, adolescentes, juventude, mulheres, travestis e transexuais, pensando os sujeitos por contexto de idade cronológica (fases da vida) e gênero. Totalizaram-se 23 artigos para discussão (29,11\% dos 79 analisados).

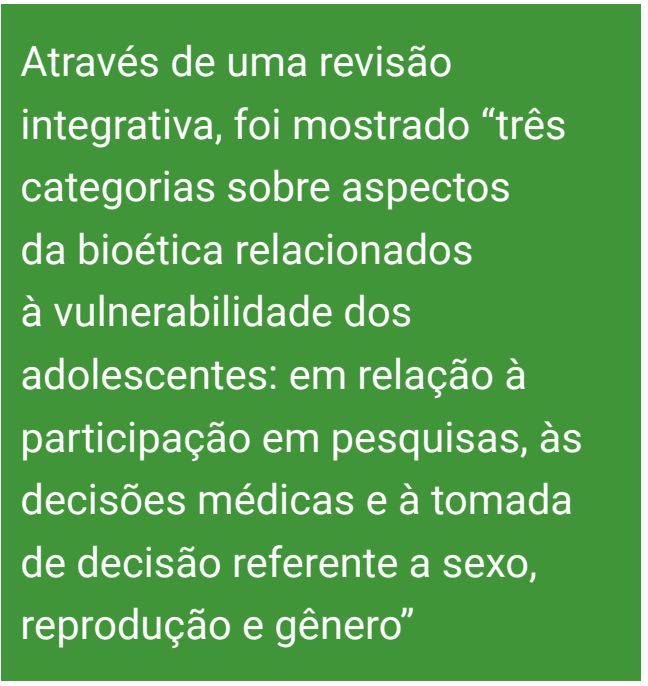

García-Scougall e Quintanilla (2015) discutiram as obrigações para proteger o embrião, indicando que, mesmo que haja fundamentações de seus direitos como humanos, estes são violados ao possibilitar a interrupção legal da gravidez. No que tange as crianças, destaca-se a problematização sobre o acesso a saúde pediátrica de imigrantes, principalmente por estarem em um país diferente da sua nacionalidade (Capella, 2012). Nesta faixa de idade, juntamente com os idosos, a vulnerabilidade é maior, pois, além de não terem desenvolvido suas capacidades próprias, também são prejudicados por dependerem de outros para serem cuidados, os quais determinarão "o grau de desenvolvimento que irão alcançar" (Capella, 2012, p.192). Além disso, destaca-se a preocupação com crianças de rua, estando em situação precária, indo para as ruas, muitas vezes, por terem sofrido ou presenciado violência física e sexual dentro das residências, demandando obrigatoriamente das responsabilidades jurídicas do Estado, para que sejam protegidas de suas condições indefesas e emancipá-los "o mais plenamente possível como um ser humano" (Gómez, Sevilla \& Álvarez, 2008, p.223).

Através de uma revisão integrativa, foi mostrado "três categorias sobre aspectos da bioética relacionados à vulnerabilidade dos adolescentes: em relação à participação em pesquisas, às decisões médicas e à tomada de decisão referente a sexo, reprodução e gênero" (Santos et al., 2017, p.77). Quanto às decisões de questões médicas, os adolescentes não têm autonomia para realizá-las; no que tange a sua participação em pesquisa e prática clínica, concluiu-se que não existe consenso em critérios, bem como a falta de amparo legal neste assunto (Santos et al., 2017). Ainda, os universitários 
aparecem como sujeitos vulneráveis por participarem frequentemente de pesquisas que não respeitam inteiramente a autonomia de escolha na participação como fundamento ético (já que grande parte participa somente por ter ações passivas frente a influências de caráter coercitivo ou persuasivo), mesmo que os pesquisadores utilizem outras fundamentações de sentidos ético e legal (Sitta, Bretanha, Beraldinelle, Sales-Peres \& Sales-Peres, 2011). A participação de crianças em pesquisa também é levantada no trabalho de Figueira (2010), principalmente na utilização do consentimento informado assinado por pais de recém-nascidos, que não entendem, muitas vezes, os riscos associados à participação, consentindo voluntariamente para tal.

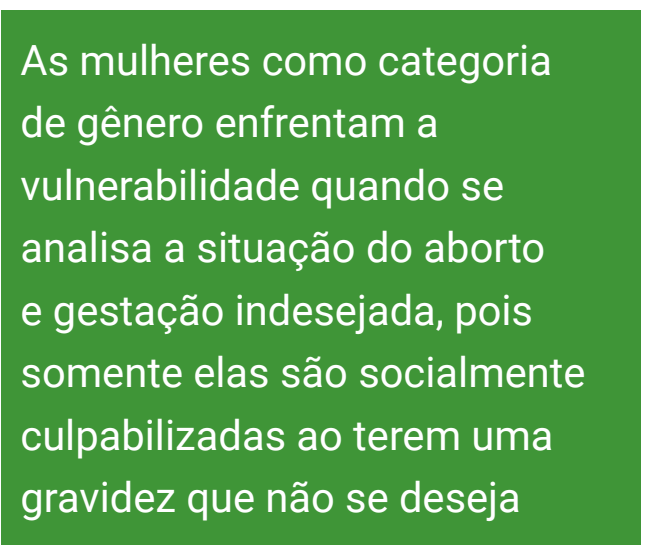

Os aspectos referentes a sexo, reprodução e gênero, onde se levantaram problemas de identidade de gênero, transexualidade, divergências de padrões legais e aparos sociais e, por fim, decisões sobre "procedimentos visando à manutenção da fertilidade em adolescentes com câncer", são vistas como problemáticas de vulnerabilidade de adolescentes (Santos et al., 2017, p.77), e também de transexuais como um todo. Considerando o acesso de transexuais a serviços de saúde, visualiza-se uma dificuldade de atendimento, indo dos serviços básicos até, principalmente, suas necessidades específicas, ficando a mercê de automedicações e tratamentos informais que não garantem segurança e privados de uma plena cidadania (Guimarães Junior, 2007).

As mulheres como categoria de gênero enfrentam a vulnerabilidade quando se analisa a situação do aborto e gestação indesejada, pois somente elas são socialmente culpabilizadas ao terem uma gravidez que não se deseja, sem poder de escolha na continuação ou não, vítimas de um sistema de valores patriarcal que determinam os papéis sociais de gênero, e não permitem o exercício da autonomia da mulher, sendo que não se pode argumentar que informações sobre contracepção são disponíveis em todas as esferas sociais, não havendo prejuízos quanto à situação geográfica, cultural e socioeconômica das mulheres (Sandi \& Braz, 2010). Além disso, preocupa-se com a autonomia e responsabilidade de grávidas adolescentes, que precisam cuidar e proteger a si e da criança que gera (Cortés, 2014). Dessa forma, a bioética aparece como uma área que possibilita, junto com a saúde pública, reflexões visando "à igualdade, à justiça e ao desenvolvimento das relações humanas" quando levantada a discussão do aborto (Sandi \& Braz, 2010, p.148).

Ressaltam-se ainda os problemas de acesso à saúde demandados por transexuais idosos, pois nesta fase da vida, são mais vulneráveis nestes aspectos, e não podem limitar-se aos tratamentos pensados a partir de políticas de saúde heteronormativas, exigindo profissionais de saúde preparados para atender este grupo, tendo a Bioética da Proteção importante papel no cuidado e defesa de sua cidadania (Guimarães Junior, 2007).

Concernente ainda à população idosa é imperativo que haja tratamento especial para que esteja protegida dignamente, dada à fase de vida que se encontra, considerando 
que fazem parte de "um grupo etário desvalorizado, excluído e silenciado", visto o aumento de suas necessidades (Ramos Vergara \& Arenas-Massa, 2015, p.33, tradução nossa) e cuidado (Burla, Pessini, Siqueira \& Nunes, 2014). Ainda, se faz necessário, com fundamentação jurídica, estatutos que garantam sua autonomia, existindo respeito a seus direitos como cidadãos, além de socialmente ressaltar a importância que este grupo tem na transmissão de valores, e seu importante papel dentro da estrutura familiar, criando uma estrutura societária (e jurídica) sem distinções que tragam malefícios de acordo com a fase da vida (Ramos Vergara \& Arenas-Massa, 2015).

\subsection{Saúde, doença e pesquisa}

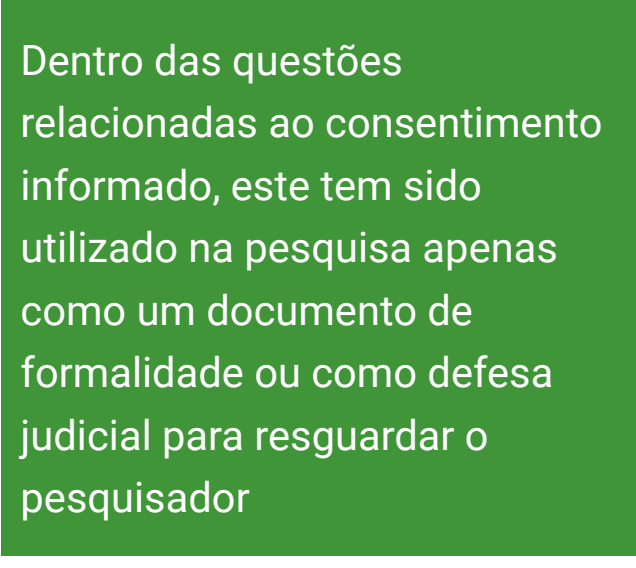

Nesta categoria, foram correlacionados os subgrupos sujeitos de pesquisa (animais humanos ou não humanos), pessoas doentes, com transtorno ou doença mental, pessoas com deficiências, pacientes em geral, com falta de saúde e também profissionais de saúde. Totalizaram-se 49 artigos para discussão (62 \% dos 79 analisados).

Sendo assim, dentro da problemática dos sujeitos de pesquisa, encontraram-se discussões quanto ao consentimento de sua participação, onde Santos et al. (2017, p.74) afirmaram que "o assentimento da criança e do adolescente para fins de pesquisa, diagnóstico ou tratamento é tema complexo e sem consenso na literatura", sendo que estas "incluem a definição do que vem a ser consentimento, a idade a partir da qual investigadores deveriam obtê-lo e quem deveria estar envolvido no processo da obtenção". Além disso, levantouse a problemática do conhecimento de seus direitos como participantes (LobatoVictoria \& Pichardo-García, 2013), principalmente nos países em desenvolvimento, sendo quesito importante no consentimento. Para proteção dos sujeitos, destacamse os pontos elencados pela DUBDH, que servem parâmetro ético para avaliar as pesquisas (Rippel, Medeiros \& Maluf, 2016).

Braz e Schramm (2011) pesquisaram a utilização de pacientes com transtornos mentais como sujeitos de pesquisa, voltando-se a utilização do Termo de Consentimento Livre e Esclarecido (TCLE), concluindo que existe uma dificuldade de realização de experimentos com este grupo, mesmo que esses sejam necessários para conhecer cientificamente as doenças com intenção da busca por curas, visto também em Morais (2010). 0 conhecimento deve ser produzido a partir do respeito com o participante e com fundamentações éticas para que seja realizada sua devida proteção (Cosac, 2017; D’Espíndula \& França, 2016). Ainda, que se a autonomia do paciente nessa situação não for respeitada através do pleno consentimento da participação de pesquisas, torna-se uma vulnerabilidade (Braz \& Schramm, 2011; E. H. R. Almeida, 2010). 
Dentro das questões relacionadas ao consentimento informado, este tem sido utilizado na pesquisa apenas como um documento de formalidade ou como defesa judicial para resguardar o pesquisador (Díaz, 2009; Santos \& Emmerich, 2011). É importante sua utilização primordialmente como respeito ao pesquisado, como portador de dignidade, mesmo que originalmente o documento venha como exigência dos participantes em terem amparo jurídico na sua autonomia em pesquisas (Díaz, 2009). Esta, por sua vez, pode ser prejudicada por fatores intrínsecos como os distúrbios mentais - cabendo aos médicos ou a medicina criar soluções- e extrínsecos, como a pobreza e analfabetismo, sendo trabalho da política superar estes fatores (Cosac, 2017). Ressalta-se também que o devido

\section{Ressalta-se também que o}

devido consentimento, uma

vez que não somente uma

formalidade, mas com o

verdadeiro esclarecimento,

possibilita uma decisão

consciente de aceitar ou não os

procedimentos propostos consentimento, uma vez que não somente uma formalidade, mas com o verdadeiro esclarecimento, possibilita uma decisão consciente de aceitar ou não os procedimentos propostos (Silva, 2017, p.37).

Outros problemas enfrentados por pesquisas são as práticas como o double standard, que é "a adoção de duplos padrões éticos para desenvolver pesquisas em países centrais e periféricos" (Cosac, 2017, p.22) e o imperialismo moral, situação onde tenta-se converter pesquisadores de países periféricos a adotarem medidas dos países ricos, "violando vários princípios dos direitos humanos" (Cosac, 2017, p.27), além do próprio poder de influência de grandes corporações e países desenvolvidos na realização de pesquisas em países periféricos. A bioética é, então, ponte de diálogo em âmbito internacional, devendo primar pelo respeito à dignidade humana na realização de pesquisas (Cosac, 2017) e proteger os mais debilitados (Ayala, 2016).

0 consentimento informado é utilizado também no âmbito hospitalar, dentro da relação médico-paciente, como indicou Silva (2017), trazendo reflexões acerca da dificuldade de adultos com a saúde comprometida. No caso de situação de internação, a fragilidade é frente ao medo da possibilidade da interrupção da vida, somada a possível falta de esclarecimento quanto aos procedimentos que estão sendo ou serão tomados em relação a sua enfermidade, sendo a informação uma "garantia de compreensão adequada pelo indivíduo para que possa deliberar sobre o melhor caminho para si e para seu tratamento". Problemática que aparece também na realização de testes genéticos mascarada com fins diversos, os quais podem vir a ser fonte de descriminação pelos seus resultados, a exemplo do diagnóstico de traço de anemia falciforme em atletas, com o agravante do desrespeito à sua confidencialidade e privacidade, aspectos básicos na ética em pesquisa (Guedes \& Reis, 2015).

Dentro da relação médico-paciente, de acordo com Ortona e Fortes (2015, p.115), são procurados médicos que coloquem os interesses dos pacientes à frente dos seus, buscando um profissional virtuoso e que prime pelo bem-estar, utilizando para fundamentação da pesquisa o conceito de ética das virtudes a partir de Edmund Pellegrino e David Thomasma. Entretanto, mostraram que a autonomia não é tão considerada nos cuidados em saúde como a beneficência, que reconhece a vulnerabilidade do paciente como uma condição resultante de estar doente. 
A boa vontade e beneficência como dever, a partir de uma fundamentação da moral de Kant, são possíveis de serem aplicada quando se olha (no sentido de ajuda) pessoas com deficiências mentais extremas, sendo como uma orientação ("para não sermos indiferentes" as dificuldades alheias) ou como um ordenamento moral de execução (Barbosa-Fohrmann, 2015, p.119).

A partir de uma reflexão sobre pessoas com deficiência em uma sociedade que coloca o desenvolvimento da tecnologia como seu foco principal, Reyes (2016) visualizou uma exclusão e marginalização desse grupo, existindo obstáculos que impedem a participação da vida em comunidade e, mesmo que a tecnologia

A qualidade de vida, como

política pública de saúde,

apresentase como dever ético

de ajuda aos que necessitam

superar sua condição de

fragilidade, principalmente

na oferta de seus direitos e

necessidades mais básicas,

além de sua inserção no

contexto social, sendo papel da

bioética a não maleficência possibilite sua consciência, é preciso ficar atento as eventuais implicações de controle que limitem suas vidas. A bioética, dentro desse contexto, age como mediação entre vida digna e o desenvolvimento científico, primando pela primeira (Reyes, 2016). Ainda, a bioética precisa ser inserida em um contexto de mediação de problemas relacionados à vida, procurando dar suporte as pessoas com doenças, ressaltando-se as negligenciadas (Andrade \& Rocha, 2015).

A qualidade de vida, como política pública de saúde, apresentase como dever ético de ajuda aos que necessitam superar sua condição de fragilidade, principalmente na oferta de seus direitos e necessidades mais básicas, além de sua inserção no contexto social, sendo papel da bioética a não maleficência (Correa, 2011). Alguns conflitos e dilemas morais emergem do dia a dia do profissional de saúde, desgastado psicologicamente por presenciar duras decisões, estando em contato com a finitude da vida e significação da morte diariamente. Visualizase como exemplo as angústias dos profissionais de saúde -mais especificamente enfermeiros- frente ao processo de doação de órgãos para transplante, os quais sofrem com a dor dos outros e se percebem em condição de sofrimento, oferecendo a bioética como possibilidade de ressignificar conceitos e auxiliar na tomada de decisão com base em seus valores, além do auxílio da própria instituição de saúde com cuidado psicológico (Limas, 2012). Dentro da temática de transplante de órgãos, existem preocupações quanto ao avanço dessa nova tecnologia, sendo importante fundamenta-las dentro da discussão da bioética, moral e filosófica (Corgozinho, Gomes \& Garrafa, 2012).

Por fim, Menezes, Priel e Pereira (2011, p.957) apresentam uma ferramenta intitulada Sistematização da Assistência de Enfermagem (SAE), que permite uma autonomia do profissional através do reconhecimento dessa sistematização a partir da execução de padrões de assistência, permitindo "uma aproximação do enfermeiro junto ao paciente, tanto no momento da sua elaboração quanto na prestação do cuidado, sua maior competência". Entretanto, considera uma vulnerabilidade se este não for instruído corretamente e não receber suporte das instâncias superiores, importantes condições para que o profissional execute seu trabalho com compromisso e responsabilidade. 


\subsection{Condições de exclusão social, econômica, cultural e política}

Nesta categoria, foram correlacionados os subgrupos população em pobreza, imigrantes, pessoas em situação de rua e vulnerabilidade socioeconômica. Totalizaramse 15 artigos para discussão ( $19 \%$ dos 79 analisados).

Como já visto na primeira categoria, as crianças imigrantes ou em situação de rua destacam-se no que tange à problemática, onde estes têm sua exclusão, dentre outros motivos, associada principalmente à pobreza, sendo que nas primeiras essa situação

Visualiza-se que a falta de

assistência de saúde também é

uma problemática diretamente

vinculada à pobreza e

desigualdade, uma vez que as

populações nesta condição

são prejudicadas no acesso

aos serviços dessa natureza

por dependerem das políticas

do estado que não são sempre

eficientes e percorrem um

caminho com diversas barreiras existe tanto no lugar de origem como no seu lugar de destino, e a pobreza aparece como um fator que dificulta sua situação (Capella, 2012). Já as crianças em situação de rua buscam seus rendimentos na prostituição ou em furtos/roubos (Gómez et al., 2008). Ainda sobre este grupo, Sotero $(2011$, p. 814$)$ indicou que convivem a todo o momento com dificuldades, estando "mais sujeita à dor, fome, frio, à morte prematura e violenta" e é isto que sobrefaz sua condição a dos demais e, por este motivo, são "vulnerados" e demandam auxílio para que saiam dessa situação, seja de procedência do âmbito político ou de orientação moral para com estes.

Correa (2011, p.25) preocupou-se com os direitos humanos ao afirmar que a "pobreza e falta de desenvolvimento social e econômico" têm importante destaque na sua violação, e seu enfrentamento deve ser o início das preocupações, principalmente no que tange ao "direito a vida e o direito a assistência justa em saúde", sendo que esta discussão é presente desde o primórdio da bioética no México até hoje em dia. O direito a saúde, especificamente dos imigrantes no Brasil é discutida por Guerra e Ventura (2017, p.27), que através de uma revisão de literatura buscando por publicações que abordassem a temática, indicaram que é um dos "pontos mais sensíveis para a concretização da inserção e integração à sociedade", por isso, a importância de práticas inclusivas que respeitem seus direitos e sua cultura, principalmente no que toca ao acesso a informação em sua língua nativa, incentivando a criação de políticas que ampliem e concretizem este acesso como direito dessa população.

Visualiza-se que a falta de assistência de saúde também é uma problemática diretamente vinculada à pobreza e desigualdade, uma vez que as populações nesta condição são prejudicadas no acesso aos serviços dessa natureza por dependerem das políticas do estado que não são sempre eficientes e percorrem um caminho com diversas barreiras, onde Corgozinho e Oliveira (2016, p.439) afırmaram que "as situações de desigualdade econômica, a vulnerabilidade social e as inequidades em saúde estão intimamente ligadas", sendo que "a bioética [...] conclama com emergência o princípio ético da equidade previsto na DUBDH".

A DUBDH também foi vista por Caetano e Garrafa (2014), ao construírem um plano de comunicação para que esta seja vista e amplamente conhecida, fundamentando no 
maior esclarecimento das populações consideradas vulneráveis sociais, uma vez que estas, por diversos motivos (como os econômicos) são marginalizadas por não terem acesso à informação, como a referida Declaração; e, uma vez que a conhecem, podem ser participantes ativas de discussões que são amparadas por esta e, dessa forma, ter seu direito de participação na vida política respeitado e exercido.

A bioética ambiental surge, então, da irresponsabilidade do homem em seu relacionamento com a natureza, ordenando novos imperativos que pudessem fundamentar moralmente essa relação
Nascimento e Martorell (2013, p.426) destacaram a necessidade de incluir no conceito de "vulnerabilidade socioeconômica", diálogos emergentes das "relações raciais, de gênero, etárias e de orientação sexual", que são condições presentes em países periféricos, exemplificando também a preocupação com esses critérios no que tange as possíveis condições de vulnerabilidade em pesquisa. Ou seja, correlacionam as categoriais 1, 2 e 3 expostas neste trabalho, indicando a bioética da intervenção como uma ferramenta crítica quanto à hierarquização social através de relações de poder (principalmente o econômico, mas também de relação racial, de orientação sexual, papeis de gênero e etc.). Por fim, destaca-se o conceito de vulnerabilidade social, indicada por Corgozinho e Oliveira (2016, p.436) como tendo "seu significado voltado ao contexto de desproteção, de pessoas ou populações excluídas socialmente e, consequentemente, atingidas pelas iniquidades em saúde".

\subsection{Meio ambiente}

Foram relacionados dois artigos nesta categoria, sendo que um deles discute a importância da bioética ambiental no enfrentamento da vulnerabilidade do planeta, e outro as fundamentações éticas na problemática da crise hídrica.

Com uma nova maneira de consumir e produzir, os efeitos ao meio ambiente começam a ter notória representação através das repercussões negativas de catástrofes ambientais, as quais resultaram na morte de vidas humanas, sendo que antes os efeitos causados pelos homens não eram questionados, pois acreditavam na infinitude da natureza. A bioética ambiental surge, então, da irresponsabilidade do homem em seu relacionamento com a natureza, ordenando novos imperativos que pudessem fundamentar moralmente essa relação (Braña \& Grisólia, 2012). Fischer, Cunha, Rosaneli, Molinari e Sganzerla (2016) indicaram a crise hídrica e a preocupação com a água do planeta como necessários de serem guardados e discutidos pela bioética ambiental. Ainda, que mesmo sabendo da sua finitude, não se veem mobilizações significativas quanto ao consciente uso do recurso e a resolução do problema que afetará significativamente a vida humana e do planeta, visto sua grandeza e complexidade, demandando o envolvimento de diversos atores que precisam ser consensualmente responsabilizados para terem ações conjuntas (Fischer et al., 2016).

A problemática ambiental, a partir da noção de que o mundo é habitado por todos e que não existem mais barreiras para os problemas desse cunho, passou a ser percebida como um problema a ser resolvido conjuntamente de maneira global, e não mais 
locais (Braña \& Grisólia, 2012). Utilizando como fundamentação teórica o princípio responsabilidade, a partir da conceituação de Hans Jonas (2006), Braña e Grisólia (2012) indicaram que este princípio baseia-se na necessidade de fundamentos éticos para guiar as ações humanas, incluindo as transformações e modificações do homem na natureza, visto a atual capacidade de realizá-las de forma definitiva, sem poder esperar a regeneração da natureza que outrora era possível, uma

A problemática ambiental, a partir da noção de que o mundo é habitado por todos e que não existem mais barreiras para os problemas desse cunho, passou a ser percebida como um problema a ser resolvido conjuntamente de maneira global, e não mais locais vez que era responsável por si mesma. A bioética, fundamentada nas questões ambientais já vivenciadas pela humanidade, aparece como uma questionadora da responsabilidade com as futuras gerações e sobrevivência humana e do planeta, já que "a própria vulnerabilidade da natureza, provocada pela intervenção técnica do homem, provoca questionamentos sobre a forma de enxergar a ética a ser pensada", podendo utilizar da análise bioética para assessorar as decisões quanto ao desenvolvimento tecnocientífico (Braña \& Grisólia, 2012, p.45). Para levantar a necessidade discussões de cunho ético junto às questões ambientais, realizando uma pesquisa sobre esse interesse no meio científico, mais especificamente sobre a crise hídrica, Fischer et al. (2016, p.596) concluíram uma limitada preocupação deste, impossibilitando "a identificação de grupos vulneráveis", sendo importante então "a identificação dos agentes e pacientes morais e as vulnerabilidades relacionadas a crise hídrica para que seja possível avançar em busca de uma solução consensual e justa para este problema complexo e global".

A problemática ambiental, a partir da noção de que o mundo é habitado por todos e que não existem mais barreiras para os problemas desse cunho, passou a ser percebida como um problema a ser resolvido conjuntamente de maneira global, e não mais locais (Braña \& Grisólia, 2012). Utilizando como fundamentação teórica o princípio responsabilidade, a partir da conceituação de Hans Jonas (2006), Braña e Grisólia (2012) indicaram que este princípio baseia-se na necessidade de fundamentos éticos para guiar as ações humanas, incluindo as transformações e modificações do homem na natureza, visto a atual capacidade de realizá-las de forma definitiva, sem poder esperar a regeneração da natureza que outrora era possível, uma vez que era responsável por si mesma. A bioética, fundamentada nas questões ambientais já vivenciadas pela humanidade, aparece como uma questionadora da responsabilidade com as futuras gerações e sobrevivência humana e do planeta, já que "a própria vulnerabilidade da natureza, provocada pela intervenção técnica do homem, provoca questionamentos sobre a forma de enxergar a ética a ser pensada", podendo utilizar da análise bioética para assessorar as decisões quanto ao desenvolvimento tecnocientífico (Braña \& Grisólia, 2012, p.45). Para levantar a necessidade discussões de cunho ético junto às questões ambientais, realizando uma pesquisa sobre esse interesse no meio científico, mais especificamente sobre a crise hídrica, Fischer et al. (2016, p.596) concluíram uma limitada preocupação deste, impossibilitando "a identificação de grupos vulneráveis", sendo importante então "a identificação dos agentes e pacientes morais e as vulnerabilidades relacionadas a 
crise hídrica para que seja possível avançar em busca de uma solução consensual e justa para este problema complexo e global".

\section{Considerações finais}

A visualização da vulnerabilidade através de categorias possibilita à bioética identificar os grupos mais fragilizados ou esquecidos, e desse modo, reforçar a atenção, o diálogo e a prática da equidade, a fim de superar essa condição. Por mais que as categorias tenham sua singularidade, identifica-se que existe uma interligação entre os diálogos, principalmente ao que concerne ao âmbito da saúde.

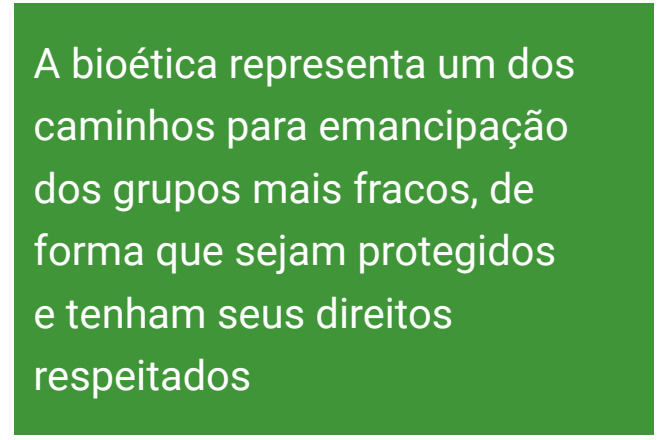

A limitada visão antropocêntrica da bioética atual torna-se um empecilho para a proteção da vida extra-humana. Embora desde a sua origem, a bioética tenha se voltado ao âmbito da saúde, seja no seu acesso ou nos problemas emergentes da rotina médica, bem como na pesquisa e prática clínica, visualiza-se a necessidade de maior atenção e dedicação a outras áreas. É imperativo que a bioética exercite pensar mais o meio ambiente e o planeta dentro das discussões de vulnerabilidade, uma vez que também são formas de vida, susceptíveis a grandes feridas e desastres, causados principalmente pelo homem, assim como imaginou Potter (1971) na sua definição.

A bioética representa um dos caminhos para emancipação dos grupos mais fracos, de forma que sejam protegidos e tenham seus direitos respeitados. Para tanto, precisa-se de apoio, empoderamento e conscientização. Assim sendo, pode-se afirmar que as virtudes que o ser humano necessita para se desenvolver e chegar a ser um agente racional, livre e independente são as mesmas que precisam ser usadas para fazer frente à fragilidade da vida em sua totalidade. Para superar o discurso antropocêntrico, é preciso que os bioeticistas consigam questionar a função do homem no reino da natureza, de modo com que o mesmo possa se compreender como parte disso, e também seu fruto, conseguindo então identificar e contribuir para superar a vulnerabilidade da natureza.

\section{Referências bibliográficas}

Almeida, E. H. R. (2010). Dignidade, autonomia do paciente e doença mental. Revista Bioética, 18 (2) 381-395.

Almeida, L. D. (2010). Suscetibilidade: novo sentido para a vulnerabilidade. Revista Bioética, 18 (3) 537-548.

Andrade, B. L. A., \& Rocha, D. G. (2015). Doenças negligenciadas e bioética: diálogo de um velho problema com uma nova área do conhecimento. Revista Bioética, 23 (1) 105-113.

Ayala, M. P. (2016). Estudio exploratorio-descriptivo sobre consideraciones bioéticas presentes en la intervención a personas con discapacidad psiquiátrica en los hospitales de día de la región del Maule. Acta Bioethica, 22 (2) 303-314. 
Barbosa-Fohrmann, A. P. (2015). Boa vontade e beneficência para pessoas com deficiência mental extrema? Revisitando a teoria moral de Kant. [Versión digital] Revista Bioética y Derecho, $35,108-120$. Recuperado de http://revistes.ub.edu/index.php/RBD/article/view/14285/17540

Becchi, P. (2008). La vulnerabilità dela vita: contributi su Hans Jonas. Genova: Editora La Scuola di Pitagora.

Braña, G. M. R., \& Grisólia, C. K. (2012). Bio(ética) ambiental: estratégia para enfrentar a vulnerabilidade planetária. Revista Bioética, 20 (1) 41-48.

Braz, M., \& Schramm, F. R. (2011). Bioética e pesquisa em saúde mental. [Versión digital] Ciênc. saúde coletiva, 16 (4) 2035-2044. Recuperado de http://www.scielo.br/pdf/csc/v16n4/v16n4a02.pdf

Burla, C., Pessini, L., Siqueira, J. E., \& Nunes, R. (2014). Envelhecimento e doença de Alzheimer: reflexões sobre autonomia e o desafio do cuidado. Revista Bioética, 22 (1) 85-93.

Caetano, R., \& Garrafa, V. (2014). Comunicação como ferramenta para divulgar e promover a Declaração Universal sobre Bioética e Direitos Humanos. Revista Bioética, 22 (1) 34-44.

Capella, V. B. (2012). Ética de la asistencia primaria a los niños de procedencia internacional. [Versión digital] Acta Bioethica, 18 (2) 189-198. Recuperado de http://www.scielo.cl/pdf/abioeth/v18n2/art07.pdf

Corgozinho, M. M., \& Oliveira, A. A. S. (2016). Equidade em saúde como marco ético da bioética. Saúde Soc. São Paulo, 25 (2) 431-441.

Corgozinho, M. M., Gomes, J. R. A. A., \& Garrafa, V. (2012). Transplantes de medula óssea no Brasil: dimensão bioética. Revista Latinoamericana Bioética, 12 (1) Edición 22, 36-45.

Correa, F. J. L. (2011). Pobreza, vulnerabilidad y calidad de vida en América Latina: retos para la bioética. Acta Bioethica, 17 (1) 19-29.

Cortés, M. S. (2014). Relevo de autonomía, para agenciar doblemente la vida, en el embarazo en la adolescência. Revista Colombiana de Bioética, (9) nº especial, 138-192.

Cosac, D. C. S. (2017). Autonomia, consentimento e vulnerabilidade do participante de pesquisa clínica. Revista Bioética, 25 (1) 19-29.

Crippa, A., Loureiro, F., \& Gomes, I. (2016). Vulnerabilidade social na doença de Alzheimer: busca por Direitos. [Versión digital] Revista Latinoamericana de Bioética, 16 (1) 198-219. Recuperado de http://www.scielo. org.co/pdf/rlb/v16n1/v16n1a11.pdf

Cunha, T., \& Garafa, V. (2017). Vulnerability. A key principle for Global Bioethics? Cambridge Quarterly of Healthcare Ethics, 25 (2) 197-208.

Díaz, F. A. G. (2009). Aspectos bioéticos del consentimiento informado em investigación biomédica com población vulnerable. [Versión digital] Revista Latinoamericana de Bioética, 9 (2) 8-27. Recuperado de http://www.redalyc.org/pdf/1270/127020306002.pdf

D’Espíndula, T. S., \& França, B. H. S. (2016). Aspectos éticos e bioéticos na entrevista em pesquisa: impacto na subjetividade. Revista Bioética, 24 (3) 495-502.

Figueira, A. C. S. (2010). Consentimento e proteção de adultos e crianças: dilemas comuns e peculiares em países em desenvolvimento. Revista Bioética, 18 (3) 691-703.

Fischer, M. L., Cunha, T. R., Rosaneli, C. F., Molinari, R. B., \& Sganzerla, A. (2016). Crise hídrica em publicações científicas: olhares da bioética ambiental. Revista Ambiente e Água, 11 (3) 586-600. 
Garrafa, V. (2005). Inclusão social no contexto político da Bioética. Revista Brasileira de Bioética, 1 (2) 122-132.

García-Scougall, J. P., \& Quintanilla, G. R. C. (2015). Fundamentación de los derechos humanos del embrión. [Versión digital] Perspectiva Bioética, 19 (2) 264-277. Recuperado de http://www.scielo.org.co/pdf/ pebi/v19n2/v19n2a06.pdf

Gómez, M. L., Sevilla, M. L., \& Álvarez, N. (2008). Vulnerabilidad de los niños de la calle. Acta Bioethica, 14 (2) 219-223.

Guedes, C., \& Reis, D. (2015). Pesquisas genéticas, prognósticos morais e discriminação genética: um estudo de caso sobre traço falciforme. Physis Revista de Saúde Coletiva, 25 (3) 729-751.

Guerra, K., \& Ventura, M. (2017). Bioética, imigração e assistência à saúde: tensões e convergências sobre o direito humano à saúde no Brasil na integração regional dos países. Caderno de Saúde Coletiva, 25 (1) 123-129.

Guimarães Junior, A. R. (2007). A Bioética da Proteção e a População Transexual Feminina. (Dissertação de Mestrado). Escola Nacional de Saúde Pública Sergio Arouca, Rio de Janeiro.

Jonas, H. (2004). O princípio vida: fundamentos para uma biologia filosófica. Tradução de Carlos Almeida Pereira. Petrólolis: Editora Vozes.

Jonas, H. (2006). O princípio responsabilidade: ensaios de uma ética para a civilização tecnológica. Tradução de Marijane Lisboa e Luiz Barros Montez. Rio de Janeiro: Contraponto/Ed. PUC-Rio.

Limas, A. A. F. (2012) Doação de órgãos para transplante: conflitos éticos na percepção do profissional. Mundo Saúde, 36 (1) 27-33.

Lobato-Victoria, A. C., \& Pichardo-García, L. M. G. (2013). ¿En qué medida es verdad que los sujetos de investigación comprenden sus derechos? Perspectivas Bioéticas, 17 (1) 49-57.

Menezes, S. R. T., Priel, M. R., \& Pereira, L. L. (2011). Autonomia e vulnerabilidade do enfermeiro na prática da Sistematização da Assistência de Enfermagem. [Versión digital] Revista da Escola de Enfermagem da USP, 45 (4) 953-958. Recuperado de http://www.scielo.br/pdf/reeusp/v45n4/v45n4a23.pdf

Morais, I. M. (2010). Vulnerabilidade do doente versus autonomia individual. Rev. Bras. Saúde Matern. Infant., 10 (Supl. 2) S331-S336.

Nascimento, W. F., \& Martorell, L. B. (2013). A bioética de intervenção em contextos descoloniais. Revista Bioética, 21 (3) 423-431.

Neves, M. P. (2006). Sentidos da vulnerabilidade: característica, condição, princípio. Revista Brasileira de Bioética, 2 (2) 157-172.

Organização das Nações Unidas para a Educação, a Ciência e a Cultura [UNESCO]. (2006). Declaração Universal sobre Bioética e Direitos Humanos. Portugal. Recuperado de: http://unesdoc.unesco.org/ images/0014/001461/146180por.pdf

Ortona, C., \& Fortes, P. (2015). Journalists want virtuous physicians? An analysis by the model of Ethic of Virtues, in reference to Beneficence, according to Pellegrino and Thomasma. [Versión electrónica] Acta Bioethica, 21 (1) 109-116. Recuperado de http://www.scielo.cl/pdf/abioeth/v21n1/art14.pdf

Potter, V. R. (1971). Bioethics: bridge to the future. Englewood Cliffs, N. J. Prentice-Hall, 205.

Ramos-Vergara, P., \& Arenas-Massa, A. (2015). Algunas conceptualizaciones acerca de la dignidad del anciano en bioderecho. Perspectiva Bioética, 19 (1) 25-35. 
Reyes, R. C. M. (2016). Discapacidad y tecnosocieda. Revista Latinoamericana de Bioética, 16 (2) 118-139.

Rippel, J. A., Medeiros, C. A., \& Maluf, F. (2016). Declaração Universal sobre Bioética e Direitos Humanos e Resolução CNS 466/2012: análise comparativa. Revista Bioética, 24 (3) 603-612.

Sandi, S. F., \& Braz, M. (2010). As mulheres brasileiras e o aborto: uma abordagem bioética na saúde pública. Revista Bioética, 18 (1) 131-153.

Santos, D. O., Gomes, F. A., Teixeira, K. R., Roever, L., Fuzissaki, M. A., Faleiros, T., \& Lima, T. C. (2017). Vulnerabilidade de adolescentes em pesquisa e prática clínica. Revista Bioética, 25 (1) 72-81.

Santos, M. L., \& Emmerich, A. (2011). O consentimento livre e esclarecido e a vulnerabilidade do sujeito de pesquisa. Revista Bioética, 19 (2) 553-561.

Schramm, F. R. (2008). Bioética da Proteção: ferramenta válida para enfrentar problemas morais na era da globalização. Revista Bioética, 16 (1) 11-23.

Silva, M. F. (2017). Consentimento informado: estratégia para mitigar a vulnerabilidade na assistência hospitalar. [Versión electrónica] Revista Bioética, 25 (1) 30-38. Recuperado de http://www.scielo.br/pdf/ bioet/v25n1/1983-8042-bioet-25-01-0030.pdf

Sitta, E. I., Bretanha, A. C., Beraldinelle, R., Sales-Peres, A., \& Sales-Peres, S. H. C. (2011). Universitários como sujeitos de pesquisa: aspectos éticos e legais. Caderno de Saúde Coletiva, 19 (1) 117-121.

Sotero, M. (2011). Vulnerabilidade e vulneração: população de rua, uma questão ética. Revista Bioética, 19 (3) 799-817.

The National Commission for the Protection of Human Subjects of Biomedical and Behavioral Research [NCPHSBBR]. (1979). The Belmont Report: ethical principles and guidelines for the protection of human subjects of research. Washington D.C.: DHEW Publications No. (OS) 78-0012. Recuperado de https:// archive.org/stream/belmontreporteth00unit\#page/n1/mode/2up/search/vulnerab 